\title{
On estimation of occupant safety in vehicular crashes into roadside obstacles using non- linear dynamic analysis
}

\author{
Krzysztof Wilde ${ }^{1}$, Arkadiusz Tilsen ${ }^{1}$, Stanisław Burzyński ${ }^{1, *}$, and Wojciech Witkowski ${ }^{1}$ \\ ${ }^{1}$ Gdansk University of Technology, Faculty of Civil and Environmental Engineering, Department of \\ Mechanics of Materials, ul. Narutowicza 11/12, 80-233 Gdansk, Poland
}

\begin{abstract}
The article describes a comparison of two general methods of occupants safety estimation based on a numerical examples. The so-called direct method is mainly based on the HIC (Head Injury Criterion) of a crash test dummy in a vehicle with passive safety system while the indirect method uses a European standard approach to estimate impact severity level.
\end{abstract}

\section{Introduction}

The first automotive accident was registered in 1896 in Europe at speed equal to $6.4 \mathrm{~km} / \mathrm{h}$. Nowadays traffic accidents become a serious social problem. There are above 450 million drivers in Europe [1]. In 2017 there were 49 killed occupants per million citizens in EU.

Reduction of the number of fatal accidents is possible due to the use of active and passive safety car systems and road safety devices. Table 1 shows how various protection systems in frontal crashes influence the overall outcome of the accident.

Table 1. Reduction of fatal accidents due to protection systems [2].

\begin{tabular}{|c|c|}
\hline Protection system & Reduction of fatal accidents \\
\hline Airbag and seat-belt & $50 \%$ \\
\hline Only airbag & $14 \%$ \\
\hline Seat-belt & $45 \%$ \\
\hline
\end{tabular}

\section{Methods}

There are two general methods to evaluate occupant's safety. The indirect method corresponds to vehicle's dynamic response in traffic accident whereas the direct method is based on dummy that mimics the human) dynamic response.

*Corresponding author: staburzy@.pg.edu.pl 


\subsection{Indirect method}

The indirect method is the most popular in designing road restraint system due to its high efficiency and lowest costs. The method requires to analyse traffic accident using the vehicle and the obstacle. There is no possibility to evaluate passenger safety directly. According to European standard [4] occupant safety is estimated by ASI and THIV parameters. These values specify the impact severity level of the restraint system. Table 3 shows three level scale of impact severity. Level A affords a greater level of safety for the occupant of an errant car than level B, and level B greater than level C. Additionally standard [11] permits maximum values $\mathrm{THIV}=44 \mathrm{~km} / \mathrm{h}$ and ASI $=1.4$ for high energy absorbing roadside equipment.

Table 3. Impact severity level for road barriers [4].

\begin{tabular}{|c|c|c|c|}
\hline Impact severity level & \multicolumn{2}{|c|}{ Index values } \\
\hline A & $\mathrm{ASI} \leq 1.0$ & \multirow{3}{*}{ and } & \multirow{2}{*}{$\mathrm{THIV} \leq 33 \mathrm{~km} / \mathrm{h}$} \\
\cline { 1 - 2 } $\mathrm{B}$ & $\mathrm{ASI} \leq 1.4$ & & \\
\hline C & $\mathrm{ASI} \leq 1.9$ & & \\
\hline
\end{tabular}

\subsubsection{Acceleration Severity Index}

The acceleration severity index (ASI) is a function of time, computed as follow [5]:

$$
\operatorname{ASI}(t)=\left[\left(\frac{\bar{a}_{x}}{\hat{a}_{x}}\right)^{2}+\left(\frac{\bar{a}_{y}}{\hat{a}_{y}}\right)^{2}+\left(\frac{\bar{a}_{z}}{\hat{a}_{z}}\right)^{2}\right]^{0.5},
$$

where $\bar{a}_{x}, \bar{a}_{y}$ and $\bar{a}_{z}$ are the values of vehicle's center of gravity accelerations, filtered with a four-pole phaseless Butterworth low-pass digital filter with a cut-off frequency of $13 \mathrm{~Hz}$. Values in denominator are the limit values of components which are equal: $\hat{a}_{x}=12 \mathrm{~g}$, $\hat{a}_{y}=9 \mathrm{~g}$ and $\hat{a}_{z}=10 \mathrm{~g}$ (g denotes freefall acceleration). The maximum value of ASI is chosen to check the impact severity level.

\subsubsection{Theoretical Head Impact Velocity}

The theoretical head impact velocity (THIV) is represented by a point that hits the surface of the hypothetical vehicle interior. It is calculated according to procedure defined in European standard [5]. The time of flight of hypothetical head and value of THIV are calculated from horizontal velocities of the vehicle's canter of gravity and $1.2 \times 0.6 \mathrm{~m}$ rectangle which represent the interior of the vehicle.

\subsection{Direct method}

Direct method is more complicated. It takes into account the occupant body and passive safety car systems like airbags and seatbelts in traffic accident. It is also more numerically and financially expensive. Different parts of the occupant's body have different injury mechanisms. This research is focused on head dynamic response. Abbreviated Injury Score (AIS) describes severity rating of occupant. Fatality range contains items such as injuries of organs, fractures and other injuries. Table 2 shows seven step scale of AIS [1]. 
Commonly used is the head injury criterion (HIC). Table 4 shows the relation between AIS code and HIC value. The table contains also probable injury's prognosis after accident.

Table 2. Abbreviated injury score (AIS) [1].

\begin{tabular}{|c|c|c|}
\hline AIS code & Injury Level & Fatality Range \\
\hline 0 & No injury & $0.0 \%$ \\
\hline 1 & Minor & $0.0-0.1 \%$ \\
\hline 2 & Moderate & $0.1-0.4 \%$ \\
\hline 3 & Serious & $0.8-2.1 \%$ \\
\hline 4 & Severe & $7.9-10.6 \%$ \\
\hline 5 & Critical & $53.1-58.4 \%$ \\
\hline 6 & Maximum & Virtually unsurvivable \\
\hline
\end{tabular}

Table 4. HIC, AIS code and head injury [6].

\begin{tabular}{|c|c|c|}
\hline HIC & AIS & Head injury \\
\hline $135-519$ & 1 & Headache or dizziness \\
\hline $520-899$ & 2 & Unconscious less than $1 \mathrm{~h}$; linear fracture \\
\hline $900-1254$ & 3 & Unconscious $1-6 \mathrm{~h}$; depressed fracture \\
\hline $1255-1574$ & 4 & Unconscious $6-24 \mathrm{~h}$; open fracture \\
\hline $1575-1859$ & 5 & Unconscious more than $24 \mathrm{~h}$; large hematoma \\
\hline$>1860$ & 6 & Non-survivable \\
\hline
\end{tabular}

\subsubsection{Head Injury Criteria}

The head injury criteria (HIC) is based on translational accelerations of the head. It was adopted by the U.S. federal government in the Federal Motor Vehicle Safety Standards No. 208. Permissible value of HIC15 is 700. HIC formula is given by [6]:

$$
\mathrm{HIC}=\operatorname{Max}\left\{\left(t_{2}-t_{1}\right)\left[\frac{\int_{t_{1}}^{t_{2}} a(t) d t}{\left(t_{2}-t_{1}\right)}\right]^{2.5}\right\},
$$

where $a(t)$ is the dummy's head resultant acceleration and $\left(t_{2}-t_{1}\right)$ is the time interval. Most commonly used is $\mathrm{HIC} 15$ what means that time interval equal $15 \mathrm{~ms}$. With known HIC value it is possible to evaluate the probability of skull fracture [8] :

$$
p(\mathrm{HIC})=\frac{1}{\sqrt{2 \pi}} \int_{-\infty}^{\frac{\ln (\mathrm{HIC})-6.96352}{0.84664}} e^{-\frac{t^{2}}{2}} d t
$$




\section{FEM Analysis}

Four numerical non-linear dynamic analysis crash tests were carried out using LSDYNA software. The first three describe frontal vehicle accidents with rigid lighting pole at different impact velocity: 30,50 and $80 \mathrm{~km} / \mathrm{h}$. The last one is the full-scale TB11 (100 $\mathrm{km} / \mathrm{h}, 20$ degree impact angle) crash test with concrete barrier. The results from both indirect and direct described methods are compared. Finite Element Method model consist of: GeoMetro modified vehicle (including Hybrid III $50^{\text {th }}$ dummy, seatbelts, $60 \mathrm{dm}^{3}$ airbag, seat and steering column) and different obstacles as described below.

\subsection{Obstacles}

\subsubsection{Rigid lighting pole}

Lighting pole used in frontal collision is $9.7 \mathrm{~m}$ high. It is made of shell elements. Rigid material model is used due to improve calculation time. Translation motions and rotations are blocked in lowermost cross section nodes.

\subsubsection{Concrete barrier}

In the current study, concrete barrier made of 8 meters length segments is used. Barrier consist of 6 segments tied by steel connectors. Obstacle is free-standing on planar ground. Elasto-plastic steel reinforcement is included (beam elements constrained in solid elements). Continuous surface cap material model (CSCM) is used to model concrete behaviour.

\subsection{Modified GeoMetro vehicle}

Geo Metro (total mass $900 \mathrm{~kg}$ ) is the smallest vehicle used in standard crash tests [4, 5]. Freely available model was modified by adding simple rigid seat and steering column. In addition, the folded airbag is implemented using control volume formulation. It is made of shell elements which gives $60 \mathrm{dm}^{3}$ volume after filling. The three-point seatbelts are also included. Contact parts of the seatbelts is made of shell elements, the rest are made of beam elements. Seatbelt includes pre-tensioner and retractor elements to keep tension after collision. Airbag and seatbelt sensors are triggered by time control, after fulfilling the geometric condition. When sensor is triggered, the seatbelt is going to lock and pretension is induced with $12 \mathrm{~ms}$ delay. In addition, airbag is filled with $17 \mathrm{~ms}$ delay. Evaluation of modifications of Geo Metro have been presented in [10].

\subsection{Hybrid III $50^{\text {th }}$ dummy}

The FEM anthropomorphic male model of a Hybrid III $50^{\text {th }}$ dummy is used to obtain occupant responses in tests. It is made of elastic skeleton covered by rubber parts, viscous foams and viscoelastic skin. The accelerometers are located in the head, chest and pelvis. The family of Hybrid III dummies are being developed at NCAC [9]. 


\section{Results}

\subsection{Frontal crash tests}

The visualization and numerical graphs are showed for frontal collision with rigid lighting pole at $50 \mathrm{~km} / \mathrm{h}$ velocity. Visualization of the initial 0.2 seconds of collision is shown in fig. 1. Fig. 2 shows the dummy's head acceleration and HIC15 calculation range. The time history of ASI is shown in fig. 3. Qualitative character of ASI and head acceleration curves is comparable. Head velocity $\left(\mathrm{V}_{\mathrm{r}}\right)$, compared to theoretical value (THIV), is presented in fig. 4.

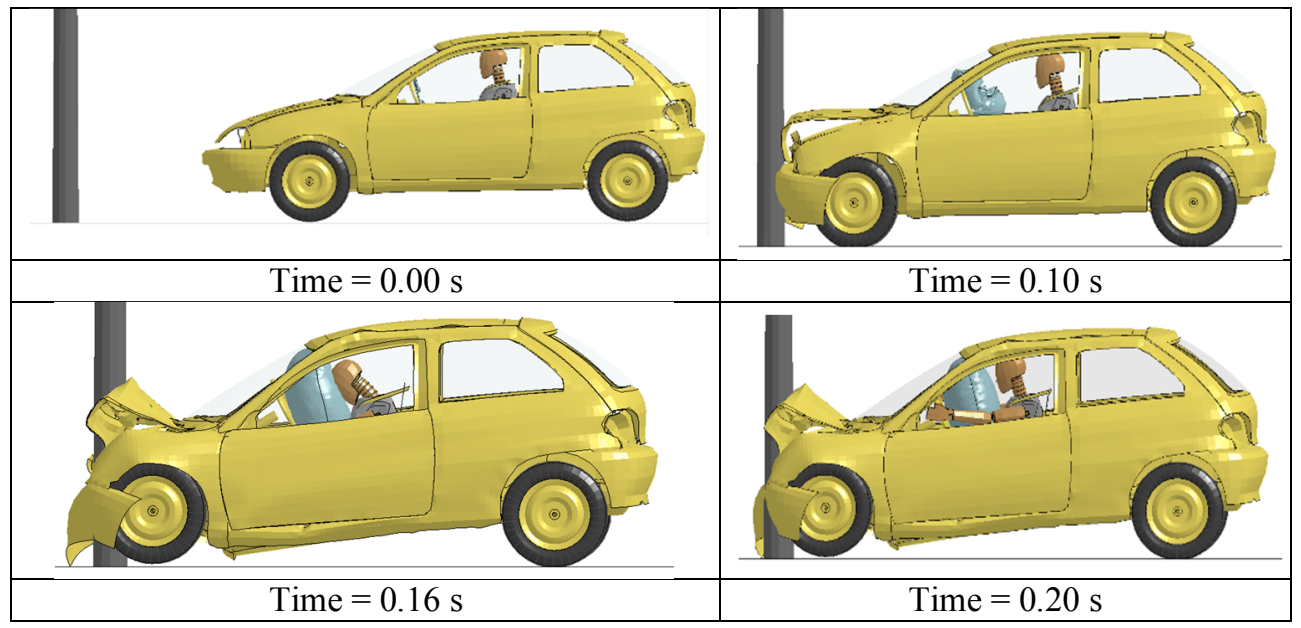

Fig. 1. $50 \mathrm{~km} / \mathrm{h}$ frontal test visualization.

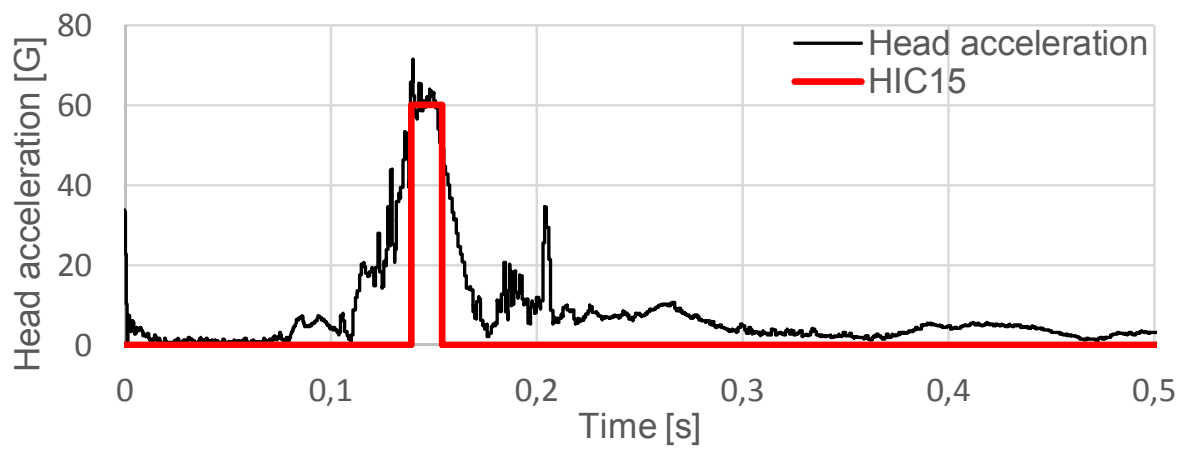

Fig. 2. $50 \mathrm{~km} / \mathrm{h}$ frontal test, head resultant acceleration and HIC15 calculation range.

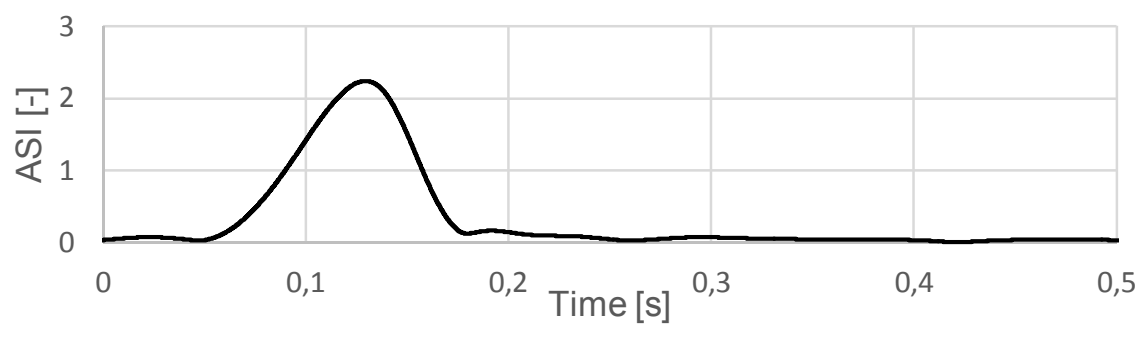

Fig. 3. $50 \mathrm{~km} / \mathrm{h}$ frontal test, ASI. 


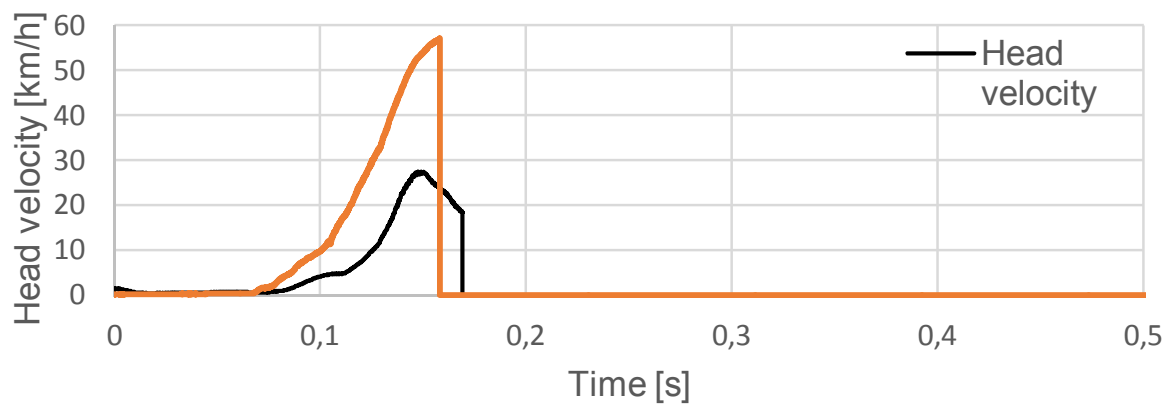

Fig. 4. $50 \mathrm{~km} / \mathrm{h}$ frontal test, head velocity until first peak $\mathrm{Vr}$ and THIV.

Table 5 shows the results of HIC15, head velocity prior to the first peak, Vr, ASI and THIV values for frontal crash test at three different velocities.

Table 5. Results for frontal crash test.

\begin{tabular}{|c|c|c|c|c|}
\hline Impact velocity [km/h] & HIC15 [-] & ASI [-] & Vr [km/h] & THIV [-] \\
\hline 30 & 43.32 & 1.14 & 16.8 & 35.7 \\
\hline 50 & 419.3 & 2.24 & 27.4 & 57.1 \\
\hline 80 & 2454 & 3.97 & 67.7 & 84.1 \\
\hline
\end{tabular}

\subsection{TB11 concrete barrier crash test}

The initial 0.3 seconds of visualization of crash test simulation with concrete barrier at velocity equal $100 \mathrm{~km} / \mathrm{h}$ and 20 degree impact angle are shown in fig. 5. Table 6 shows the results of HIC15, head velocity until first peak Vr, ASI and THIV values for TB11 crash test with concrete barrier.

Table 6. Results for TB11 concrete barrier crash test.

\begin{tabular}{|c|c|c|c|c|}
\hline Impact velocity $[\mathbf{k m} / \mathbf{h}]$ & HIC15 [-] & ASI [-] & Vr [km/h] & THIV [-] \\
\hline 100 & 17.1 & 1.53 & 21.1 & 27.0 \\
\hline
\end{tabular}

\section{Conclusions}

Table 7 shows the summary of the occupant injury estimation results using both methods. It contains probability of skull fracture calculated from HIC15 value, AIS code chosen on the basis of the HIC15 value, injury level based on the AIS code and impact severity level determined on the basis of ASI and THIV values. The D value of the impact severity level means that the results are out of scale. 


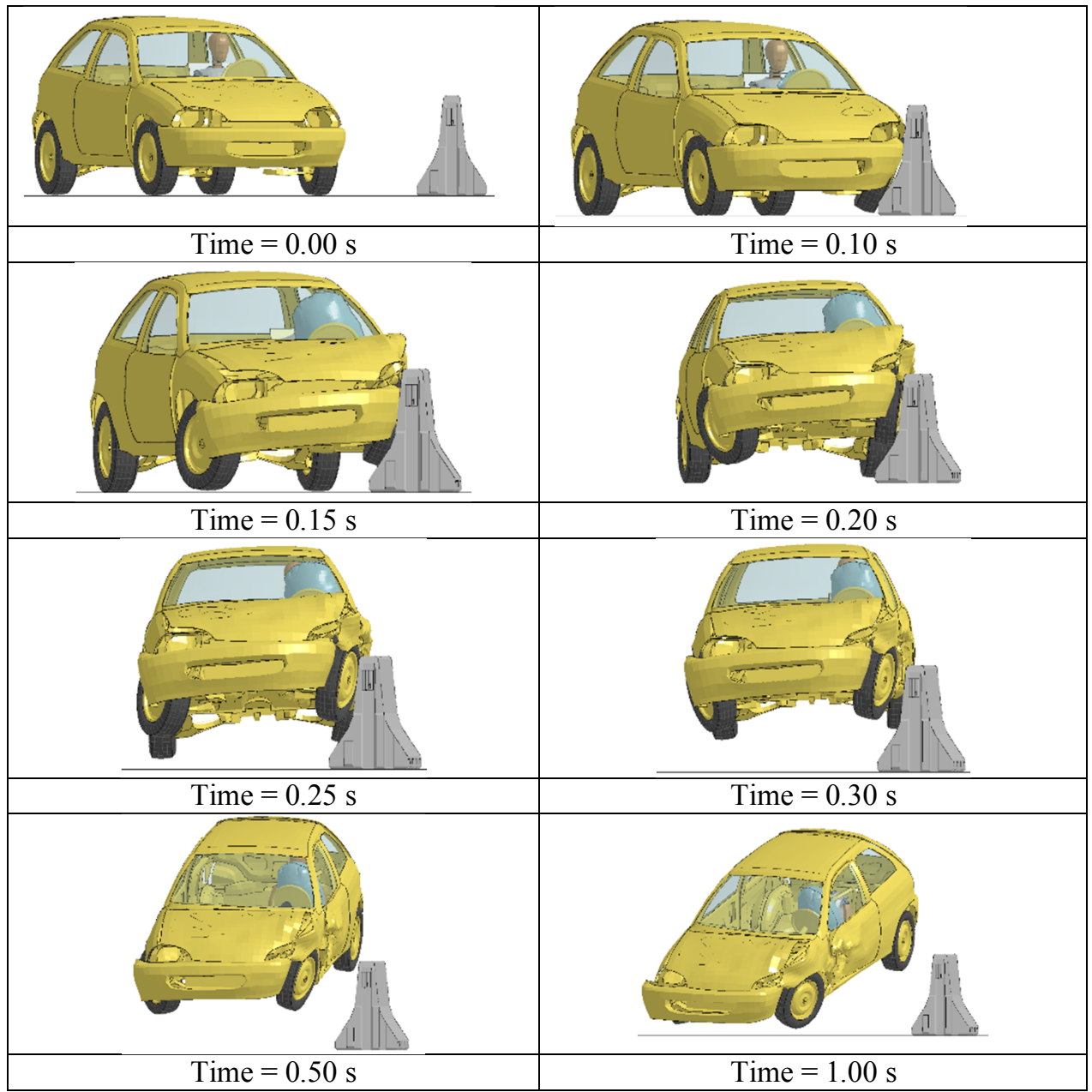

Fig. 5. TB11 crash test visualization.

The results confirm that the indirect method commonly used in the design of barriers has a large safety reserve. In the analysed frontal collision test, directly measured quantities $\left(\mathrm{HIC15}, \mathrm{V}_{\mathrm{r}}\right)$ predicts lower injury risk than those obtained by indirect methods (ASI, THIV). Even for a velocity equal to $50 \mathrm{~km} / \mathrm{h}$, the HIC15 corresponds to AIS level 1 (see table 4). Also THIV value is always higher than direct head velocity, which is affected by airbag deployment.

Concrete barrier TB11 test gives acceptable $\mathrm{C}$ impact severity index. There is very low value of direct method parameters that means there is no predicted injury. This confirms that the use of the indirect method gives very safe results.

\section{Acknowledgements}

This work was supported by the National Centre for Research and Development (NCBiR) and General Director for National Roads and Motorways (GDDKiA) under the research project "Road Safety Equipment" (contract number DZP/RID-I-67/13/NCBR/2016). 
Calculations have been carried out at the Academic Computer Centre in Gdańsk, Gdańsk University of Technology, Poland.

Table 7. Summary of the occupant injury estimation.

\begin{tabular}{|c|c|c|c|c|}
\hline Method: & \multicolumn{3}{|c|}{ Direct } & Indirect \\
\hline $\begin{array}{c}\text { Impact velocity [km/h] } \\
\text { / angle [deg] }\end{array}$ & p(HIC15) [\%] & AIS code & Injury level & $\begin{array}{c}\text { Impact } \\
\text { severity } \\
\text { level }\end{array}$ \\
\hline \multicolumn{5}{|c|}{ Frontal collision } \\
\hline $30 /-$ & 0.008 & 0 & No injury & D \\
\hline $50 /-$ & 13.7 & 1 & Minor & $\mathrm{D}$ \\
\hline $80 /-$ & 84.0 & 6 & Maximum & $\mathrm{D}$ \\
\hline \multicolumn{5}{|c|}{ Concrete barrier } \\
\hline $100 / 20$ & 0.00006 & 0 & No injury & $\mathrm{C}$ \\
\hline
\end{tabular}

\section{References}

1. L. Pelenyte-Vysniauskiene, A. Jurkauskas, Transport - 2007, 22, 269-274 (2007)

2. Sheldon, L.; Stucki, W.; Hollowell, T. Determination of frontal off set test conditions based on crash data. National Highway Traffic Safety Administration, Information Systems and Services. Paper No. 98-S 1-0-02. p. 15-35, (1998)

3. Versace, J., A review of the severity index, SAE Technical paper no. 710881; (1971)

4. EN 1317-2 : Road restraint systems - Part 2: Performance classes, impact test acceptance criteria and test methods for safety barriers including vehicle parapets

5. EN 1317-1 : Road restaint systems - Part 1: Terminology and general criteria for test methods

6. C. Andreescu, A. Clenci, Proceedings of the European Automotive Congress EAECESFA, 723-731, (2016)

7. NHTSA, Federal Motor Vehicle Safety Standards : Occupant Crash Protection. 49 C.F.R., Part 571.208, (1998)

8. Hertz E. A note on the head injury criteria (HIC) as a predictor of the risk of skull fracture. In : The 37th annual proceedings of the association for the advancement of automotive medicine, (1993)

9. P. Mohan, C-K. Park, D. Marzougui, C-D. Kan, S. Guha, C. Maurath, et al., LSTC/NCAC dummy model development. In : The 11th international LS-DYNA users conference, Detroit, USA, (2010)

10. Bruski D, Burzyński S, Chróścielewski J, Pachocki Ł, Witkowski W. On the validation of the LS-DYNA Geo Metro numerical model. MATEC Web Conf (2019); 262:10001.

11. EN-12767 Passive safety of support structures for road equipment. Requirements and test methods 